\title{
Perspectives on Food Traceability System: A Case in Chain Restaurant Franchising
}

Recently, Taiwanese chain restaurants started to establish supplier management system or systematic mechanism for quality food screening from raw material to finished product. While chain restaurants enlarged operations meeting customers' demands, supplier management in the supply chain activities is particularly important such as quality, cost, delivery time, service (Hsu and $\mathrm{Hu}, 2010$; Van der Valk and Wynstra, 2005) and safety and healthiness (Aung and Chang, 2014; Wei and Huang, 2017). Food scandals reduce consumers' trust in food safety. Understanding of the consumer's attitude towards trust and risk of food safety could reform the utility of public policy and allow expansion of the best practice in food safety problems. It is important to establish mechanism for screening and management of food safety in franchising 
industry. To achieve this objective, the food traceability system (FTS) has been introduced in many countries to reduce the uncertainties originating in the food purchasing process by providing information about the whole process from farm to table in terms of quality and safety (Choe et al., 2009). Unfortunately, there exists only few examples about food supplier management or food traceability system (FTS) in chain restaurant franchising industry. Moreover, the most small-to-medium chain restaurants lack the ability to establish ingredients supply management and traceability management mechanism.

Bosona and Gebresenbet (2013) indicated that food traceability systems are part of logistics management that capture, store, and transmit adequate information and allow the product to be checked for safety and quality control in upstream and downstream of supply chain. FTS provides franchisee with the tracing and tracking of products and the associated complete product history information. The system addresses this contemporary concept of traceability and reduce the limitations in defining food traceability and limitations in understanding the linkage between food traceability and logistics activities.

FTS are decision support systems that are directly used by the franchiser in a retail context. It can also support customer decision making and motivate sellers to charge fair prices for their products, thereby resulting in customer purchases with high satisfaction (Bharati and Chaudhury, 2004). As seen above, the goal of FTS is to collect all the information in a rigorous way related to the displacement of all different production processes of chain restaurants so that in the future can be effectively traced by all restaurants' members.

Using the focus group method, the purpose of this study is to explore the information requirements of chain restaurants' food safety system through exchanging standard communication which provides updated e-Tracking information to suppliers, headquarters, franchisees and consumers.

\section{LITERATURE REVIEW}

\section{Food Safety and Food Traceability System (FTS)}

Food safety is the inverse of food risk - the probability of not suffering from some dangerous health effects by consuming a specific food. Potential harmful substances in foods span widely and impact human health, 


\section{Chiu \& Hsieh}

from natural and environmental contaminants to agrochemicals, growth promoters, packaging components, veterinary drugs, and many more. It does not only influence the consumers' health, but also have an impact on corporation's sales (Jansen-Vullers et al., 2003), and may impact the hospitality industry as a whole. Additionally, foodborne issues directly affect consumer behavior and the level of customer satisfaction. This topic, as mentioned earlier, has become a global issue that governments all over the world become highly concerned about how to manage it. Therefore, chain restaurants must reckon food traceability as an important mechanism and establish a system to control it. Many countries have introduced FTS to reduce consumers' perceived purchase risk concerning food safety because these systems have been found to have a positive effect on customer purchases (Chang and Chen, 2009; Jiang et al., 2010). According to United States' Food Safety Modernization Act (FSMA), Food and Drug Administration (FDA) can test and verify the ingredients used in food and related products and can forcibly order enterprise to recall the products if the products are found with potential dangerous elements or undesirable residues in food products. In Japan, restaurants are trying to use the traceability system to strengthen consumer confidence in food safety. Entrepreneurs can use a unified FTS maintained by Organization of Food Distribution Structure Reform Promotion (OFSI) which provides consumers a regional products database search facility. The concept of the traceability stems from European Union under EU law; traceability means "the ability to track any food, feed, food-producing animal or substance that will be used for manufacturing food product, through all stages of production, processing and distribution". Prior research shows that some types of information systems (ISs) can play an important role in reducing information asymmetry and track the food information between sellers and consumers (Pavlou et al., 2007). These systems not only support consumers making their buying decision, they also motivate sellers to charge fair prices for their products, thereby resulting in consumer purchases with high satisfaction (Bharati and Chaudhury, 2004).

\section{Benefits of FTS}

Both Chang and Chen (2009) and Jiang et al. (2010) indicate that FTS has been introduced in many countries to reduce consumers' perceived purchase risk concerning food safety. Many studies indicate that these systems have a positive impact on customer purchases. In order to accurately and rapidly solve 
unexpected food safety issues, FTS must have a more effective organizational design and control (Trienekens and Zuurbier, 2008). The large chain restaurants have more strong incentive to adopt standard certification programs, a tool to enhance the work efficiency than small restaurants, it could serve as a source of business advantage; in terms of supply chain, the electronic pedigree can reduce transaction costs, including search costs, consultation costs and monitoring costs, in these factors, chain restaurants have an incentive to implement FTS.

FTS offers supply chain's members with information about the production timing, regional contents, and other details about the production and distribution process. When foodborne problem occurs, FTS can effectively assist product recall and support business to survive. By virtue of origin labeling program in systems, information in the supply chain reflects more transparency as well as effectively enhance quality of foods and trust between customers and sellers (Saltini and Akkerman, 2012). As seen above, continuous environmental changes and customer needs in risk control is important, however it is difficult asking small restaurants to spend hefty amount of money to implement traceability systems. Hence, headquarters of restaurants should offer traceability system architecture to suppliers, franchisees and consumers.

\section{METHODOLOGY}

In the case where food business operators establish a group and introduce a traceability system through the food chain (production, preparation/processing, distribution or sale), focus group should be formed based on the agreed basic plan for the purpose of operating the system. Our approach for the analysis of the content and data obtained through focus groups includes three phases: (1) determining and definitions and scope of focus group data to analyze it, (2) conducting the roles of FTS and identifying key drivers of food traceability in our framework, (3) integrating the results of all restaurant's members. This section also clarifies the way group interaction data was analyzed. The phases of the procedure have been presented below.

Phase 1: Definitions and scope of focus group data for analysis

Considering the aim of the study, which is to capture a range of perspectives on individual FTS problem solving strategies, we determined that four group interactions i.e. headquarters, suppliers, franchisees and consumers determine data type and analysis approach. Traceability has been defined differently depending 


\section{Chiu \& Hsieh}

on the context. General definitions have been outlined for particular food commodities or by specific actors in the food chain. Driving forces for traceability and headquarter, suppliers, franchisees interests.

Traceability used to be a market requirement for niche products but has now become a mainstream commercial requirement and trade issue. In addition to being a business strategy and market advantage, it is often described as an instrument of quality assurance for consumers. The food crises highlighted deficiencies in food safety systems and resulted in implementation of traceability systems to produce food safety and increase consumer confidence. Today, traceability is often described as a response to consumers' increasing demand for transparency with regard to geographical origin, production methods, and health and sustainability issues.

The FTS includes supplier, producers, wholesalers, retailers, consumers, governments and international bodies. Consumers' increasing health and safety consciousness is often considered an important driving force (Gellynck and Verbeke, 2001).

\section{Phase 2: Roles of FTS and identifying key driver of food traceability in our framework}

The selection of four participants was divided in two groups, one was external traceability group and the

other was internal traceability group. As a result, external traceability group was identified including information of supplier and headquarter needed to solve a FTS problem. Internal traceability was divided into units which were condensed into headquarter and supplier.

\section{-External Traceability}

External traceability refers to the difference between different industries in the upstream and downstream of the food supply chain and includes the concatenation of materials, semi-finished products and finished product information. External traceability depends on each operator implement internal traceability and pass relevant information about the goods at the time of shipment to the next producer or circulator, so the food chain needs to establish a common information communication standards, such as the international food supply system, must ensure raw materials and products product name, batch, product description, legal requirements should disclose information, batch records, information such as quality control indicators, safety inspection items, and product flow is not to be interrupted. 
The following is a description of the functional requirements of suppliers and headquarters.

\section{-Suppliers}

FTS provide several benefits and incentives for suppliers and producers. Traceability makes it possible for industry to comply with legislation, facilitate and minimize withdrawal of products, plant control, diagnose problems in production, create special products and maintain markets and consumer confidence (Golan et al., 2004). It provides the producers with documentation for own practice that can be used in business administration and marketing. Implementation of FTS acts in accordance with legislation also often been demanded by large multinational food businesses to minimize business risk and protect their branded goods (Denton, 2003; Food Standards Agency, 2002). Traceability enables industry to differentiate and market foods with subtle or undetectable so-called credence quality attributes (Golan et al., 2004; Kher et al., 2010). Thus, suppliers and producers may use traceability to verify quality of special products and to achieve preferred position as supplier.

\section{-Consumers}

FTS is perceived to give more control to the consumer within the food chain. Consumers are said to gain mainly hidden benefits from traceability. The benefit of traceability system is relatively considered as less strong driver as efficient full chain traceability system is capital and resource intensive and require significant initial investment. For example, consumers can use FTS in boycotting imported products or products produced with specific production methods. Consumers get food safety protection and the possibility to avoid specific foods and to make real choices.

\section{-Internal Traceability}

Internal traceability refers to the raw materials or products of each batch in the food chain, recording information on raw materials, process information and product flow information. There are four important concepts in internal traceability management: First is batch management of raw materials. Products covered by the system i.e. raw materials, additives, other ingredients of products, and packaging should be covered among the product line. Second is the process control of the production process, especially the opening of the manufacturing order, and the origin, mixing, transformation and processing of batches; third is the flow 


\section{Chiu \& Hsieh}

management of product batches; Fourth, the information of the aforementioned three processes must be related to each other, so it is often necessary to rely on information system to assist in the recording and processing of cumbersome information and the consequences of the selection must be understood by the intended receiver.

\section{-Headquarter}

Small- and mid-sized producers have taken advantage of the increased interest in FTSs in chain restaurant franchising. Producers are also selling through intermediate marketing channels, such as sales to local retail, restaurants, and retail distribution outlets to fulfill suppliers' and producers' needs. FTSs have the potential to extenuate consumers' health risks from poor quality or contaminated food products that can sometimes have serious life threatening consequences, as opposed to other types of information systems that are aimed at mitigating strategic, operational, or information assurance risks. Through information technology software, information systems design and producing electronic resumes can help establish a traceability systems management mechanism (Mattevi and Jones, 2016). This makes cooperative relationships and trading partnerships easier to manage, and lowers the administration burden for hubs to collaborate, therefore reducing overall costs in the supply chain.

\section{-Franchisees Needs}

Franchisees are largely concerned about FTS because they are concerned about market profits and have financial responsibilities to their consumers. Food safety was originally the driving force for implementing traceability systems. Thus, the role of customers and consumers has become more visible. Next we will take a look at the interests the different stakeholders have in traceability based on the literature.

\section{Phase 3: Integrating the results of all restaurants' members}

We analyzed the latent content by reading through the whole text and the content areas identified earlier. The latent content of each content area was divided into meaningful units that were then condensed into a description close to the text. In the third phase, we integrated the results of the first and the second phases. Therefore, all sub-categories, categories, subthemes, and the themes of each content area were reported in an integrated text. Table 1 shows these results for the integrating content areas. Traceability is the ability to 
track any food through all stages of production, processing and distribution (including importation and at retail). Traceability should mean that movements can be traced one step backward and one step forward at any point in the supply chain (see Figure 1).

\begin{tabular}{|c|c|c|c|c|}
\hline Users & Headquarter & Suppliers & Franchisees & Consumers \\
\hline $\begin{array}{c}\text { Supply chain membership } \\
\text { database }\end{array}$ & $\bullet$ & & & \\
\hline Order management & $\bullet$ & $\bullet$ & & \\
\hline Establish food resume & $\bullet$ & $\bullet$ & & \\
\hline $\begin{array}{c}\text { Food resume accomplishment } \\
\text { notice }\end{array}$ & $\bullet$ & $\bullet$ & & \\
\hline Exporting food resume & $\bullet$ & $\bullet$ & $\bullet$ & \\
\hline Maintaining food resume & $\bullet$ & $\bullet$ & $\bullet$ & \\
\hline Look up food resume & $\bullet$ & $\bullet$ & $\bullet$ & $\bullet$ \\
\hline Information feedback & $\bullet$ & $\bullet$ & $\bullet$ & $\bullet$ \\
\hline FAQ & $\bullet$ & $\bullet$ & $\bullet$ & $\bullet$ \\
\hline
\end{tabular}

Table 1. Core Operating System Functions about FTS in Chain Restaurant Franchising

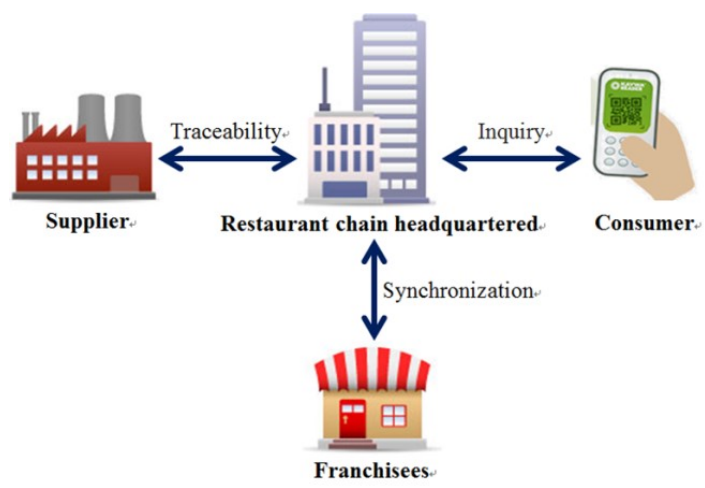

Figure 1. FTS's Information Flow Diagram

Following is a comprehensive discussion on database, storage and document production of food traceability system:

\section{-Supply chain Membership Database}

The data include names and addresses (and other contact details) of suppliers and a description of products or inputs supplied; names and addresses (and other contact details) of customers and a description of the products supplied to them. These data must provide, to the reasonable satisfaction of an authorized officer 


\section{Chiu \& Hsieh}

upon request, the following information relating to food on the food premises - (a) the name and business address of the vendor, manufacturer or packer or the name and business address of the importer; and (b) the prescribed name or, if there is no prescribed name, a name or a description of the food sufficient to indicate the true nature of the food.

\section{-Storing Information}

Concerned firms should set the storing period and storing method of the recorded information. FTS should be implemented with the following points in mind; the objectives set for introducing the traceability system, and the nature of the production, processing, and distribution of the food products concerned. Data should be organized so that it can be easily taken out when transmitting information, disclosing information to the public institutions, and doing internal auditing when storing food, store the food in such a way:

-It is protected from the likelihood of contamination.

-The environmental conditions under which it is stored will not adversely affect the safety and suitability of the food.

-Store it under temperature control.

-If it is food that is intended to be stored frozen, ensure the food remains frozen during storage.

\section{-Designating and Preserving Necessary Documents}

This study focuses on three factor FTSs depends upon: Resume information, food safety, food trust and traceability as follows:

Resume information: Using stored reports and relevant information can improve the efficiency of document management and query, share information quickly, reduce file retransmission.

Food safety: Most of the major products of the chain restaurant industry are all important sources of livelihood diet. Food safety management included the three microbial testing, food nutrition labeling, food containers and packaging.

Food trust and traceability: The process of making food i.e. from raw materials to product, through raw material procurement, manufacturing, warehousing and distribution. If foodborne issues occur, FTS can effectively assist product recall and support business to survey and make consumer to trust sellers that they would not sell poor quality products or provide inaccurate information, furthermore, helps alleviate consumer' 
s perceived purchase risk. Therefore, how to track information is most important in the food safety management.

\section{CONCLUSION}

Due to limited resources, FTS in chain restaurants is underdeveloped because the scale of restaurants is small or medium, mostly in Taiwan. Business costs and goodwill is under the influence of food safety issue. Therefore, through the establishment of tracking platform, starting from raw ingredients checks based on the entire industry as a whole import of information technology (verification, certification, quality control and distribution of the ingredients, etc.). FTS will enhance related value-added features in the hospitality by offering sharing of information and towards a more refined, customized and optimized business management. The promotion of technology development and application of the value in this study is as follows:

\section{-Reduce the risk of procurement of ingredients}

FTS will build a confidence between headquarter and franchisee. Both can use the system to search whether food quality acceptance criteria is fulfilled or not that can reduce risk of purchasing ingredients for products.

\section{- Cost Cutting}

Batch encoding can effectively control dynamic batch ingredients and FTS provides inspection report, if has any problem about food, according to the time and batch number, we can quickly grasp the number of problem to avoid wasting time and costs, furthermore, make operation more efficient.

\section{-Report immediately to improve efficiency}

Through information platform, headquarters can instantly receive feedback and connect the suppliers to rectify the main problem and also can push a reply message to consumers via individual consumers' app in short time.

\section{-Management efficiency}

This system makes the administrative procedures more simplified and optimized; also human resources can be more resilient. Enterprises can handle more orders, if they use FTS. Therefore, FTS will increase 


\section{Chiu \& Hsieh}

efficiency and improve the performance of enterprises.

-Trust between the supplier, headquarter, franchisees and consumers

Consumers can see the reports on various FTS features. This is an important function in the system that reduces information asymmetry among the supplier, headquarter, franchisees and consumers in chain restaurants.

\section{IMPLICATIONS}

Traceability is essential for business success today. FTS provides backward trace of ingredients related information to supplier's supplier and forwards ingredients related information to customer's customer. The application of the FTS not only adds value to chain restaurant franchising but also provides a system to share information and a more refined, customized and optimized business management mechanism. FTS is a powerful tool that helps companies track and trace ingredients used in manufacturing. In addition, the right FTS helps companies integrate myriad business systems. The system offers a business partner solutions and guidelines for the management of governmental import and export inspection and certification systems for foods. Additionally, FTS links the supply chain information to horizontal and vertical integration that grasp the direction of the whole batch of food production and marketing process related to health and safety aspects of the business are tightly bound to each other. The system shares the collected information and forms trustworthiness and credibility. If there is a problem, it will not only impact the level of the process but whole supply chain activities and business goodwill will come to a crisis. It is recommended that entire food chain to be covered by the system i.e. production, processing and distribution, should implement FTS. When considering what kind of information to record, the operator should make this decision in reference to the purpose of FTS and considering its effectiveness and the possible necessary cost. The decision whether to record information should be considered based on the necessities of each management system, especially in terms of the record on production, sanitation and quality management state.

\section{REFERENCES}

Aung, M. M. \& Chang, Y. S. (2014). Traceability in a food supply chain: safety and quality perspectives. Food Control, 39,172-184.

Bharati, P. \& Chaudhury, A. (2004). An empirical investigation of decision-making satisfaction in web-based decision support systems. Decision Support Systems, 37,187-197. 
Bosona, T. \& Gebresenbet, G. (2013). Food traceability as an integral part of logistics management in food and agricultural supply chain. Food Control, 33, 32-48.

Chang, H. H. \& Chen, S. W. (2009).Consumer perception of interface quality, security, and loyalty in electronic commerce. Information and Management, 46, 411-417.

Choe, Y. C., Chung, J., Park, M. \& Moon, J. (2009). Effect of the food traceability system for building trust: price premium and buying behavior. Information Systems Frontiers, 11, 167-179.

Denton, W. (2003). Trace fish: The development of a traceability scheme for the fish industry, In Luten J. B. (ed.), Quality of fish from catch to consumer: Labelling, monitoring and traceability. Netherlands: Wageningen Academic.

Gellynck, X. \& Verbeke, W. (2001). Consumer perception of traceability in the meat chain. Agrarwirtschaft, 50, 368-374.

Golan, E., Krissoff, B., Kuchler, F., Calvin, L., Nelson, K. \& Price, G. (2012).Traceability in U.S. food supply: economic theory and industry studies. Agricultural Economics Reports, 33939, United States Department of Agriculture, Economic Research Service.

Hu, H. \& Hsu, H. W. (2010).Critical factors for implementing green supply chain management practice: an empirical study of electrical and electronics industries in Taiwan. Management Research Review, 33, 586-608.

Jansen-Vullers, M.H., Dorpb, C.A.van \& Beulensb, A. J. M. (2003). Managing traceability information in manufacture. International Journal of Information Management, 23, 395-413.

Jiang, Z., Chan, J., Tan, B.C. \& Chua, W. S. (2010). Effects of interactivity on website involvement and purchase intention. Journal of The Association For Information Systems, 11, 34-59.

Kher, S. V., Frewer, L. J., De Jonge, J., Wertholt, M., Davies, O. H. \& Luijckx, N. B. L. (2010). Experts' perspectives on the implementation of traceability in Europe. British Food Journal, 112, 261-274.

Mattevi, M. \& Jones, J. A. (2016). Food supply chain: Are UK SMEs aware of concept, drivers, benefits and barriers, and frameworks of traceability? British Food Journal, 118, 1107-1128.

Pavlou, P. A., Huigang, L. \& Yajiong, X. (2007). Understand and mitigating uncertainty in online exchange relationships: A principalagent perspective. MIS Quarterly, 31, 105-136.

Saltini, R. \& Akkerman, R. (2012).Testing improvements in the chocolate traceability system: Impact on product recalls and production efficiency. Journal of Food Control, 23, 221- 226.

Trienekens, J. \& Zuurbier, P. (2008). Quality and safety standards in the food industry: Developments and challenges. International Journal of Production Economics, 113, 107-122.

Wei, Y. P. \& Huang, S. H.(2017). Food traceability system as elevating good corporate social responsibility for fast food restaurants. Cogent Business and Management. Retrieved from https://doi.org/10.1080/23311975.2017.1290891

Wendy, van der V. \& Finn, W. (2005). Supplier involvement in new product development in the food industry. Industrial Marketing Management, 34, 681-694.

\section{ACKNOWLEDGEMENT}

This work was supported by the National Science Council, Taipei, Taiwan, R.O.C., Project No. Grant MOST: 103-2622-H-328-001-CC3. 